\title{
Mutations in the sodium channel gene SCN2A cause neonatal epilepsy with late-onset episodic ataxia
}

Schwarz, N.

2016-02

Schwarz , N, Hahn , A , Bast , T, Mueller , S, Loeffler , H, Maljevic , S , Gaily , E, Prehl , I , Biskup , S, Joensuu , T , Lehesjoki , A -E, Neubauer, B A , Lerche , H \& Hedrich , U B S 2016 , ' Mutations in the sodium channel gene SCN2A cause neonatal epilepsy with late-onset episodic ataxia ' , Journal of Neurology , vol. 263 , no. 2 , pp. 334-343 . https://doi.org/10.1007/s00415-01

http://hdl.handle.net/10138/173743

https://doi.org/10.1007/s00415-015-7984-0

other

acceptedVersion

Downloaded from Helda, University of Helsinki institutional repository.

This is an electronic reprint of the original article.

This reprint may differ from the original in pagination and typographic detail.

Please cite the original version. 


\section{Mutations in the sodium channel gene $S C N 2 A$ cause neonatal epilepsy with late-onset episodic ataxia}

N. Schwarz, MD ${ }^{1}$, A. Hahn, $\mathrm{MD}^{2}$, T. Bast, $\mathrm{MD}^{3}$, S. Müller, Dipl. Biol. ${ }^{1}$, H. Löffler ${ }^{1}$, S. Maljevic, $\mathrm{PhD}^{1}$, E. Gaily, MD, $\mathrm{PhD}^{4}$, I. Prehl, Dipl. Biol. ${ }^{5}$, S. Biskup, MD, $\mathrm{PhD}^{5,6}$, T. Joensuu, $\mathrm{PhD}^{7}$, A.-E. Lehesjoki, MD, $\mathrm{PhD}^{7}$, B. A. Neubauer, $\mathrm{MD}^{2}$, H. Lerche, $\mathrm{MD}^{1}$, U.B.S. Hedrich, $\mathrm{PhD}^{1}$

${ }^{1}$ Dept. of Neurology and Epileptology, Hertie Institute for Clinical Brain Research, University of Tübingen, Tübingen, Germany; ${ }^{2}$ Department of Neuropediatrics, University Medical Clinic Giessen, Germany; ${ }^{3}$ Epilepsy Center Kork, KehlKork, Germany; ${ }^{4}$ Department of Pediatric Neurology, Children's Hospital, Helsinki University Hospital, Helsinki, Finland; ${ }^{5} \mathrm{CeGaT}$ GmbH; Dept. of Neurology with focus on Neurodegeneration, Hertie Institute for Clinical Brain Research, University of Tübingen, Tübingen, Germany; ${ }^{6}$ Hertie Institute for Clinical Brain Research, University of Tübingen, and German Center for Neurodegenerative Diseases (DZNE) Tübingen, Germany; ${ }^{7}$ Folkhälsan Institute of Genetics, Neuroscience Center and Research Programs Unit, Molecular Neurology, University of Helsinki, Helsinki, Finland

Corresponding author: $\quad$ Prof. Dr. Holger Lerche

Corresponding author's address: Department of Neurology and Epileptology,

Hertie Institute for Clinical Brain Research,

University of Tübingen,

Hoppe-Seyler-Str. 3

72076 Tübingen, Germany

Corresponding author's phone and fax: Tel.: +49-7071-29-80466, Fax: +49-7071-29-4488

Corresponding author's e-mail address: holger.lerche@uni-tuebingen.de

\section{Acknowledgements}

The authors thank all patients and their parents for participating in this study. We thank Markus Lommi, Ann-Liz Träskelin and Paula Hakala for technical assistance, Dr. Julian Schubert and Stefanie Garkisch for their help with analysis of genetic data. This work was supported by the German Research Foundation (DFG Le1030/10-2, Le1030/11-1 to HL, 416/5-1 to BAN) and the Folkhälsan Research Foundation (A-EL), partly in the frame of the EuroEPINOMICS programme of the European Science foundation. 


\begin{abstract}
Mutations in SCN2A cause epilepsy syndromes of variable severity including neonatal-infantile seizures. In one case, we previously described additional childhood-onset episodic ataxia. Here, we corroborate and detail the latter phenotype in three further cases. We describe the clinical characteristics, identify the causative $S C N 2 A$ mutations and determine their functional consequences using whole-cell patch-clamping in mammalian cells. In total, four probands presented with neonatal-onset seizures remitting after five to 13 months. In early childhood, they started to experience repeated episodes of ataxia, accompanied in part by headache or backpain lasting minutes to several hours. In two of the new cases, we detected the novel mutation p.Arg1882Gly. While this mutation occurred de novo in both patients, one of them carries an additional known variant on the same SCN2A allele, inherited from the unaffected father (p.Gly1522Ala). Whereas p.Arg1882Gly alone shifted the activation curve by $-4 \mathrm{mV}$, the combination of both variants did not affect activation, but caused a depolarizing shift of voltage-dependent inactivation, and a significant increase in $\mathrm{Na}^{+}$current density and protein production. p.Gly1522Ala alone did not change channel gating. The third new proband carries the same de novo SCN2A gain-of-function mutation as our first published case (p.Ala263Val). Our findings broaden the clinical spectrum observed with SCN2A gain-of-function mutations, showing that fairly different biophysical mechanisms can cause a convergent clinical phenotype of neonatal seizures and later onset episodic ataxia.
\end{abstract}

Key words: Epilepsy, genetics, ataxia, channelopathy, sodium channel 


\section{Introduction}

Gene discovery in epilepsy and related neurological syndromes, such as migraine, paroxysmal dyskinesia and episodic ataxia, has revealed that mutations in ion channels, transporters, or synaptic proteins play a crucial role in their pathophysiology [1-3]. These mutations affect the excitability of different neuronal subtypes and compartments. The altered excitability, sometimes provoked by typical decompensating triggers, episodically induces a dysfunction of neuronal networks in distinct brain regions thereby causing well-defined paroxysmal clinical symptoms. Beside 'pure' syndromes with only one characteristic clinical feature, several overlap syndromes with epilepsy as a core phenotype have been described $[4,5]$.

The neuronal voltage-gated $\mathrm{Na}^{+}$channel Nav1.2, encoded by the $S C N 2 A$ gene, is mutated in benign familial neonatalinfantile seizures (BFNIS), an autosomal dominant epilepsy syndrome characterized by transient seizures in the first weeks or months of life [6,7]. These mutations mainly lead to gain-of-function defects causing neuronal hyperexcitability [8,7]. More severe, non-familial phenotypes with neonatal onset seizures caused by de novo $S C N 2 A$ mutations are increasingly described [9-14]. One loss-of-function mutation causes epileptic encephalopathy with later onset [15].

We previously described a single patient with neonatal-onset, relatively severe epilepsy resolving at 13 months of age, with episodes of ataxia, myoclonus and pain starting at 18 months of age. We identified a de novo missense mutation in SCN2A showing a gain-of-function defect [3]. Here, we describe three further independent cases with neonatal-onset seizures and episodic ataxia starting in early childhood. We reveal the common clinical features, the underlying $S C N 2 \mathrm{~A}$ mutations and their pathophysiological mechanisms. 


\section{Materials and methods}

\section{Patients}

Clinical evaluation of the first new case (patient \#1) and follow-up of the previously described one (\#4) were performed in Helsinki. The other two new patients were examined at the University Clinic Giessen (patient \#2) or at the Epilepsy Center Kork (patient \#3). All patients were selected from routine clinical presentations in the respective centers and underwent subsequent genetic testing due to clinical suspicion of an SCN2A defect, since they presented highly similarly as case \#4.

\section{Molecular Genetics}

Patient \#1 underwent direct (Sanger) sequencing of SCN2A. For patients \#2 and \#3 an epilepsy gene panel screening was performed as reported previously [16]. Confirmation of the mutations and segregation was performed by Sanger sequencing. Long range PCR was used to determine if the two variants detected in patient \#2 were on the same allele.

For SCN2A sequencing genomic DNA was isolated from EDTA-blood. The coding exons and exon-intron boundaries of $S C N 2 A$ in patients \#2 and \#3, and mutation-carrying exons in their parents, were amplified (primers available upon request). SCN2A in patient \#4 and her parents was amplified (primers available upon request) by the Qiagen Multiplex PCR kit, and by the Expand Long Range PCR kit (Cat. No. 04829034001 Roche, Mannheim, Germany) on a Biometra T3 thermocycler (Biometra, Göttingen, Germany). Long range PCR products were cloned (TOPO ${ }^{\circledR}$ XL PCR Cloning Kit, Cat. No. K4700-10) and finally sequenced. For long range PCR, covering both detected variants chromosomal position 166242926-66246608 (forward: ATCGTGCCACTGCACTCCAACC, reverse: CTATCGTCTGAGTAGCCATTACGCC) was amplified resulting in a $3682 \mathrm{bp}$ fragment. Sequencing reactions were performed using ABI PRISM ${ }^{\circledR}$ BigDye ${ }^{\circledR}$ Terminator v3.1Cycle Sequencing Kit (Applied Biosystems, Weiterstadt, Germany). Capillary electrophoresis was conducted on an ABI PRISM® 3100 Genetic Analyzer (Applied Biosystems, Weiterstadt, Germany) or an ABI 3730 DNA Analyzer (Perkin Elmer, Foster City, CA, U.S.A.).

\section{Mutagenesis}

To engineer the mutations into the adult splice variant of the human $\mathrm{Na}_{\mathrm{V}} 1.2$ channel, site-directed mutagenesis was performed using Quickchange ${ }^{\circledR}$ II XL (Agilent Technologies, Santa Clara, CA, USA; primers are available upon request) for the R1882G mutation and GoTaq ${ }^{\circledR}$ Long PCR Master Mix (Promega Corporation, Madison, WI, USA; primers are available upon request) for the G1522A and G1522A + R1882G mutations. Before used in experiments, the mutant cDNA was fully resequenced to verify the introduced mutations and exclude any additional sequence alterations. GlaxoSmithKline (Brentford, UK) kindly provided the human $\mathrm{Na}^{+}$channel subunits $\mathrm{h} \beta_{1}$ and $\mathrm{h} \beta_{2}$ in the pCLH vector. The hygromycin coding region in the vector was exchanged with the sequence coding for either enhanced green fluorescent protein (EGFP) or CD8 marker genes to obtain pCLH-hß1-EGFP and pCLH-hß2-CD8 [3,17]. 


\section{Transfection and expression in tsA201 cells}

Human ts A201 cells were cultured at $37^{\circ} \mathrm{C}$, with $5 \% \mathrm{CO}_{2}$ humidified atmosphere and grown in $89 \%$ Dulbecco's modified Eagle medium (Invitrogen, Carlsbad, CA,USA) $+10 \%(\mathrm{v} / \mathrm{v})$ foetal bovine serum (PAN-Biotech GmbH, Aidenbach, Germany) + 1\% L-Glutamin 200 mM (Biochrom GmbH, Berlin, Deutschland). Transfections using Mirus TransIT®-LT1 reagent (Madison, WI 53711 USA) were performed for transient expression of wild-type or mutant $\mathrm{Na}^{+}$ channel $\alpha$-subunits together with $\beta_{1}$ - and $\beta_{2}$-subunits in tsA-201 cells. For co-expression of $\alpha$ - and both $\beta$-subunits $2.4 \mu \mathrm{g}$ of total DNA (2.0 $\mu \mathrm{g} \alpha$-subunit, $0.2 \mu \mathrm{g} \beta_{1}$-subunit and $0.2 \mu \mathrm{g} \beta_{2}$-subunit) was transfected in a molar ratio of 1:1:1. AntiCD8 antibody-coated microbeads (Dynabeads M450, Dynal, Norway) were suspended in phosphate buffered saline and added to the cells. Cells positive for both CD8 antigen and EGFP fluorescence were used for electrophysiological recordings.

\section{Western Blot}

For protein identification we applied $35 \mu \mathrm{g}$ per line of total cell lysate on a 6\% SDS gel. After separation and blotting, the Protran ${ }^{\circledR}$ Nitrocellulose Membranes was blocked with 5\% skim milk powder/PBS/0,1\% Tween 20 and incubated with mouse monoclonal anti-SCN2A antibody $1: 500$ (overnight, $4{ }^{\circ} \mathrm{C}$ ) in $1 \%$ skim milk powder/PBS/0,1\% Tween 20 . As secondary antibody HRP conjugated goat anti-mouse serum 1:10.000 (1 h, RT) was used. Western Blots were developed using the Mini-PROTEAN® Tetra Cell according to the manufactures procedures. Quantification of signals was performed using ImageJ software (NIH, Bethesda, MD). Expression of Nav1.2 proteins were normalized to corresponding Vinculin signals in total lysates and pooled from different experiments.

\section{Electrophysiology}

Standard whole-cell patch clamp recordings were performed using an Axopatch 200B amplifier, a Digidata 1320A digitizer and pCLAMP 8 data acquisition software (Axon Instruments, Union City, CA, USA), as has been described before [7]. Leakage and capacitive currents were automatically subtracted using a pre-pulse protocol (-P/4). Currents were filtered at $5 \mathrm{kHz}$ and digitized at $20 \mathrm{kHz}$. Cells were visualized using an inverted microscope (Axio-Vert.A1; Zeiss). All recordings were performed at room temperature of $21-23^{\circ} \mathrm{C} . \mathrm{Na}^{+}$currents of $1-12 \mathrm{nA}$ were recorded from transfected tsA201 cells 10 min after establishing the whole cell configuration. Borosilicate glass pipettes had a final tip resistance of 1-2 M $\Omega$ when filled with internal recording solution (see below). We carefully checked that the maximal voltage error due to residual series resistance after up to $95 \%$ compensation was always $<5 \mathrm{mV}$. The pipette solution contained (in mM): $5 \mathrm{NaCl}, 2 \mathrm{MgCl}_{2}, 5$ EGTA, 10 (4-(2-hydroxyethyl)-1-piperazineethanesulphonic acid (HEPES), 130 CsF (pH 7.4, 290 mOsm). The bath solution contained (in $\mathrm{mM}$ ) $140 \mathrm{NaCl}, 4 \mathrm{KCl}, 1 \mathrm{MgCl}_{2}, 2 \mathrm{CaCl}_{2}, 5 \mathrm{HEPES}, 4$ Dextrose (pH 7.4, 300 mOsm). 
Voltage clamp protocols and data analysis: The activation curve (conductance-voltage relationship) was derived from the current-voltage relationship obtained by plotting the peak current over various step depolarizations $(7.5 \mathrm{mV}$ steps from a holding potential of $-140 \mathrm{mV}$ ) according to

$$
g(V)=\frac{I}{\left(V-V_{r e v}\right)}
$$

with $\mathrm{g}$ being the conductance, I the recorded peak current at test potential $\mathrm{V}$, and $\mathrm{V}_{\text {rev }}$ the apparent observed $\mathrm{Na}^{+}$reversal potential.

The voltage-dependence of activation was fit with the following Boltzmann function:

$$
g(V)=\frac{g_{\max }}{\left\{1+\exp \left[\left(V-V_{1 / 2}\right) / k_{V}\right]\right\}}
$$

with $g$ being the conductance, I the recorded current amplitude at test potential $\mathrm{V}, \mathrm{V}_{\text {rev }}$ the $\mathrm{Na}^{+}$reversal potential, $\mathrm{g}_{\max }$ the maximal conductance, $\mathrm{V}_{1 / 2}$ the voltage of half-maximal activation and $\mathrm{k}_{\mathrm{V}}$ a slope factor. Steady-state inactivation was determined using $300 \mathrm{~ms}$ conditioning pulses to various potentials followed by the test pulse to $-20 \mathrm{mV}$ at which the peak current reflected the percentage of non-inactivated channels. A standard Boltzmann function was fit to the inactivation curves:

$$
I(V)=\frac{I_{\max }}{\left\{1+\exp \left[\left(V-V_{1 / 2}\right) / k_{\mathrm{V}}\right]\right\}}
$$

with I being the recorded current amplitude at the conditioning potential $\mathrm{V}, \mathrm{I}_{\max }$ being the maximal current amplitude, $\mathrm{V}_{1 / 2}$ the voltage of half-maximal inactivation and $\mathrm{k}_{\mathrm{V}}$ a slope factor. For analysis of the time constants of fast inactivation, the cell membrane was depolarized to various test potentials from a holding potential of $-140 \mathrm{mV}$ to record $\mathrm{Na}^{+}$currents. A second-order exponential function was best fit to the time course of fast inactivation during the first $70 \mathrm{~ms}$ after onset of the depolarization, yielding two time constants. The weight of the second slower time constant was relatively small. Only the fast time constant, named $\tau_{\mathrm{h}}$, was therefore used for data presentation in the 'Results' section. Persistent $\mathrm{Na}^{+}$ currents (ISS, for the 'steady-state' current) were determined at the end of depolarizing pulses, lasting $95 \mathrm{ms,} \mathrm{to} \mathrm{different}$ test potentials and are given relative to the initial peak current ( $\left.\mathrm{I}_{\mathrm{PEAK}}\right)$. Recovery from fast inactivation was recorded from holding potentials of $-140 \mathrm{mV}$. Cells were depolarized to $-20 \mathrm{mV}$ for $100 \mathrm{~ms}$ to inactivate all $\mathrm{Na}^{+}$channels and then repolarized to various recovery potentials $(-80,-100$ or $-120 \mathrm{mV})$ for increasing duration. A second-order exponential 
function with an initial delay was best fit to the time course of recovery from inactivation. The faster time constant with the much larger relative amplitude, $\tau_{\text {rec }}$, is shown for data evaluation.

\section{Data and statistical analysis}

Traces were displayed off-line with Clampfit software of pClamp 10.0 (Axon Instruments). Graphics were generated using a combination of Microsoft Excel (Microsoft Corporation, Redmond, WA, USA), and Origin (version 6.1; OriginLab Inc., Northampton, MA, USA) software, statistics were performed using SigmaStat 3.1 (Statcon). All data were tested for normal distribution. For statistical evaluation t-test was used for comparing two groups. For comparing more than two groups, ANOVA on ranks (Kruskal-Wallis-Test) with Dunn's posthoc test for not normally distributed data or one-way ANOVA (Bonferroni posthoc test) was used when data sets were normally distributed. All data are

shown as means \pm SEM, "n" gives the number of cells. For all statistical tests, significance with respect to control is indicated on the figures using the following symbols: ${ }^{*} \mathrm{p}<0.05,{ }^{* *} \mathrm{p}<0.01,{ }^{* * *} \mathrm{p}<0.001$. 


\section{Results}

\section{Clinical characterization.}

All four identified patients showed very similar phenotypes with neonatal-onset focal or generalized seizures remitting almost completely at 5-13 months old, followed by episodes of ataxia at least once a month starting in early childhood. All clinical data are summarized in Table 1 and more detailed case descriptions are given in Online Resource 1.

Epileptic seizures in patient \#1 (Fig. 1a), carrying only the novel de novo missense mutation p.Arg1882Gly (R1882G) started at two days old with bilateral tonic-clonic seizures with reduced oxygen saturation and unresponsiveness. The seizures were initially pharmacoresistant to phenobarbitone (PB) and valproate (VPA) but stopped by five months of age with no recurrences. Since the age of 3.7 years, episodes with slurred speech, ataxia, nausea and headache occur 1-2 times per month lasting minutes to hours. In patient \#2, who carries both $\mathrm{R} 1882 \mathrm{G}$ and also the inherited variant p.Gly1522Ala (G1522A), multifocal clonic and tonic-clonic seizures lasting 10-120 seconds occurred in the fourth week of life, and were well controlled by PB. The girl's further course was uncomplicated until a series of generalized tonicclonic seizures during a febrile infection at five months old. PB was changed to VPA and no further seizures occurred after the age of 5 months, also after VPA was finally discontinued at 7 years old. From 20 months of age on, episodes characterized by headache, slurred speech, impaired balance and ataxic gait occurred 1-10 times per week lasting 1-5 minutes.

Patient \#3 (Fig. 1c), carrying the same de novo missense SCN2A mutation as the previously described patient \#4 [3] (p.Ala263Val, A263V), presented immediately after birth with a marked muscular hypotonia and sleepiness. His development was slightly retarded. A first cluster of bilateral tonic seizures occurred at 7 days of life which was resistant to different medications (see Table 1). Oxcarbazepine (OXC) and levetiracetam (LEV) were started at 4 months of age, and the patient remained seizure-free so far from 7 months on. At 22 months, the parents reported an episode of ataxia with mild symptoms starting in the morning and inability to walk or stand in the afternoon. Further similar attacks with ataxic gait occurred since then every 10 to 14 days, lasting hours to one day. Formerly described patient \#4 presented with neonatal-onset seizures with hypomotor semiology followed by tonic-clonic seizures as described previously [3]. During treatment with phenytoin (PHT), seizures became much less frequent at the age of 13 months. Since then, he has only suffered from three isolated generalized tonic-clonic seizures at the age of 3.5, 6.5 and 14.5 years. The habitual headache-ataxia episodes started at 18 months old and were pharmacoresistant [3] until now.

Episodic ataxia in all four patients responded poorly to any of the medications tried so far (see Table 1, Online Resource 1 and discussion). 
Genetics. In both patients $\# 1$ and $\# 2$ we identified the novel missense mutation c.5644C $>$ G, p.Arg1882Gly (R1882G; GeneBank NM_021007.2, NC_000002.11). Sequencing of the parents revealed that the mutation occurred de novo in both patients. In addition, the missense variant c.4565G $>$ C, p.Gly1522Ala (G1522A; rs147522594) was identified in patient \#2. Rs147522594 was also detected in the healthy father (Fig. 1c) and occurs with an allele frequency of 0.00073\% (allele count: 89/121922) within the Exome Aggregation Consortium (ExAC). Both G1522 and R1882 are completely conserved in all other 28 studied vertebrates (www.1000genomes.org). R1882G is not known to be present in unaffected individuals (www.1000genomes.org/, http://exac.broadinstitute.org/, http://www.ncbi.nlm.nih.gov/SNP/). DNA Sequencing of a cloned long range PCR fragment revealed that both variants are present on the identical allele in patient \#2.

Diagnostic gene panel sequencing was performed in patient \#3 [16]. The same mutation (c.788C>T, p.Ala263Val) as previously described in patient \#4 was detected in SCN2A [3]. Sequencing of both parents revealed that the mutation occurred de novo

Functional studies. Electrophysiological analysis was first performed for the wild type (WT) channel in comparison with the de novo R1882G mutant, which was detected as the only SCN2A mutation in patient \#1 (Fig 2). This analysis revealed a significant hyperpolarizing shift of the activation curve for mutant channels (Fig. 2d). We did not find significant differences for any other recorded gating parameter including current density (Fig. 2, Table 2, Online Resource 1 Fig. S1).

Since patient \#2 carries both the de novo R1882G mutation and the inherited variant G1522A on the same allele, we additionally analyzed mutant channels carrying (i) G1522A alone, and (ii) both G1522A and R1882G (Fig. 3). Mutant G1522A alone did not reveal any significant changes compared to WT channels. Interestingly, the double mutant channel did not show changes of the activation curve (Fig. 3e), as described above for R1882G alone. In contrast, the most prominent effect for the double mutation was a 1.7 -fold increase in current density compared to the other three clones, i.e. WT, G1522A and R1882G alone (Fig. 3d, Table 2). In addition, we found a significant shift of the steadystate fast inactivation curve towards more depolarized potentials only for channels carrying both variants (Fig. 3, Table 2). Consistent with the increase in current density (as a measure for the number of functional channels in the membrane), Western blot analysis of transfected tsA201 cells -to study the amount of protein expression- revealed that the total $\mathrm{Na}_{\mathrm{V}} 1.2$ protein amount was significantly increased only in channels carrying both variants in comparison to the WT (Fig. $4)$.

We thus found differential gain-of-function effects for $\mathrm{Nav} 1.2$ channels carrying either the R1882G mutation alone or both variants, R1882G and G1522A. In both cases (R1882G alone or in combination with G1522A), the changes predict an increase of membrane excitability in neurons expressing mutant $\mathrm{Na}_{\mathrm{v}} 1.2$ channels. 


\section{Discussion}

We here describe patients carrying two different $S C N 2 A$ mutations and comprising neonatal -onset seizures and childhood-onset episodic ataxia as the two main features. When we published the first case in 2010, it was not clear if the de novo A263V mutation in $S C N 2 A$ was responsible alone for the main clinical symptoms, as migraine was a common feature in both branches of the family which could have influenced the phenotype of patient \#4 [3]. Detection of a second patient (\#3), with the same clinical key symptoms carrying the same mutation occurring independently de novo, now strongly suggests that this mutation is causative for both the seizures and episodic ataxia. Patients \#1 and \#2, carrying another de novo mutation in the same gene (in patient \#2 occurring in combination with an inherited known rare polymorphism), corroborate these findings that the phenotype is caused by $S C N 2 A$ gain-of-function mutations. This widens the spectrum of disorders combining epilepsy with other paroxysmal neurological symptoms such as dyskinesia or ataxia, which could be attributed to the expression of respective genes in different brain areas inducing an episodic dysfunction of neuronal networks [18-23].

The clinical characteristics of these patients in comparison to other $S C N 2 A$-associated syndromes are that seizures recurred more frequently and persisted longer than in typical BFNIS and that those were more difficult to treat [24]. In contrast to more severe epileptic encephalopathies [9-15], the seizures still remitted after 5-13 months (except for few occasional later seizures in patient \#4). Since drugs have been discontinued in patient \#2, seizure freedom can be attributed to spontaneous remission, whereas this remains unclear in the other cases, as treatment has been continued (patients \#1 and \#3) or restarted after seizure relapse during a drug-free period (patient \#4). Notably, seizures in patient \#3 responded well to the $\mathrm{Na}^{+}$channel blocker oxcarbazepine. Attacks of episodic ataxia with onset ranging 15 months to 3.7 years of age were the most important symptom beside the seizures. Episodic headache was an additional feature occurring in all patients, although rare and uncertain in one, and could be accompanied by back pain, discomfort and vomiting. Treatment of episodic ataxia is more difficult. Patients \#1 and \#4 did not respond to acetazolamide. In addition, 4-aminopyridine, which works well in the clinically rather similar episodic ataxia type $2[25,26]$, did not help patient \#4. The effect of $\mathrm{Na}^{+}$channel blockers, which work very well in the clinically distinct episodic ataxia type 1 with much shorter attacks triggered by sudden movements after rest [27-29], is not yet entirely clear in our patients. Theoretically, this group of antiepileptic drugs should counteract a gain-of-function of SCN2A mutations. There is increasing evidence that patients with severe early-onset epilepsies due to $S C N 2 A$ mutations do respond to $\mathrm{Na}^{+}$channel blockers [30]. However, network effects are difficult to predict and could influence the response to such drugs - also in a distinct way in different brain regions - as shown recently for the hippocampus [31].

Our previous and the here presented electrophysiological data clearly indicate that different gain-of-function effects of the detected mutations in SCN2A cause the clinical phenotype. Whereas the A263V mutation causes mainly an increased 
persistent $\mathrm{Na}^{+}$current [3], the de novo mutation $\mathrm{R} 1882 \mathrm{G}$ found in patient $\# 1$ showed a hyperpolarizing shift of the activation curve. In contrast, the combination of both variants in the same channel subunit, as detected in patient \#2, leads to a prominent increase in current density, confirmed by a larger amount of produced protein, and a depolarizing shift of the steady-state inactivation curve (but no shift of the activation curve). Until now, many BFNIS-associated $S C N 2 A$ mutations - partly showing other gain-of-function mechanisms - rather exhibited a decrease in current density or cell surface expression, which however rarely reached statistical significance $[3,7,17,32]$. This confirms the peculiar importance of the increased current density of the combined variants found in patient \#2. All observed effects predict an increased $\mathrm{Na}^{+}$inflow and a neuronal hyperexcitability, which can explain the dysfunction of cortical or cerebellar networks causing the clinical symptoms of our patients.

We have previously suggested that the age-dependent occurrence of seizures and remission in BFNIS could be due to the high Nav1.2 channel expression in axon initial segments of hippocampal and cortical pyramidal neurons early in development and their partial replacement by Nav1.6 channels with increasing maturation [7]. This mechanism could also contribute to seizure remission in the additional three cases. Although the episodic ataxia found in the studied patients might have many different causes, one hypothesis for later onset ataxia could be due to a delayed upregulation of $\mathrm{Na}_{\mathrm{V}} 1.2$ in cerebellar granule cells $[7,33]$.

Interestingly, different substitutions of the arginine at position 1882 (R1882Q and R1882L) have been identified in two de novo cases exhibiting epileptic encephalopathy [11] and intractable seizures, optic atrophy, severe intellectual disability, brain abnormalities and muscular hypotonia [13]. Furthermore, the A263V mutation has also been described as occurring de novo in monozygotic twins with Ohtahara syndrome and other unique neuropathologic abnormalities [34], and a A263T mutation has been identified in a patient with a different type of early-onset epileptic encephalopathy [12]. These observations indicate that not only the mutation determines the clinical phenotype, but that other factors such as the genetic background have to play a role in genotype-phenotype relationships.

In summary, we here identified four patients with a common clinical phenotype (neonatal seizures and later onset ataxia) caused by SCN2A mutations, which enlarges the spectrum of neurological SCN2A-related phenotypes. 


\section{Conflicts of interest}

The authors declare that they have no conflict of interest.

\section{Ethical standards}

Informed consent was obtained from the parents of all four patients. All procedures were in accordance with the Declaration of Helsinki and were approved by the local ethical review boards. 


\section{References}

1. Lerche H, Shah M, Beck H, Noebels J, Johnston D, Vincent A (2013) Ion channels in genetic and acquired forms of epilepsy. The Journal of physiology 591 (Pt 4):753-764. doi:10.1113/jphysiol.2012.240606

2. Russell JF, Fu Y-H, Ptácek LJ (2013) Episodic neurologic disorders: syndromes, genes, and mechanisms. Annual review of neuroscience $36: 25-50$

3. Liao Y, Anttonen AK, Liukkonen E, Gaily E, Maljevic S, Schubert S, Bellan-Koch A, Petrou S, Ahonen VE, Lerche H, Lehesjoki AE (2010) SCN2A mutation associated with neonatal epilepsy, late-onset episodic ataxia, myoclonus, and pain. Neurology 75 (16):1454-1458. doi:10.1212/WNL.0b013e3181f8812e

4. Kasteleijn-Nolst Trenite D, Parisi P (2012) Migraine in the borderland of epilepsy: "migralepsy" an overlapping syndrome of children and adults? Epilepsia 53 Suppl 7:20-25. doi:10.1111/j.1528-1167.2012.03711.x

5. Berg AT, Plioplys S (2012) Epilepsy and autism: is there a special relationship? Epilepsy \& behavior : E\&B 23 (3):193-198. doi:10.1016/j.yebeh.2012.01.015

6. Berkovic SF, Heron SE, Giordano L, Marini C, Guerrini R, Kaplan RE, Gambardella A, Steinlein OK, Grinton BE, Dean JT, Bordo L, Hodgson BL, Yamamoto T, Mulley JC, Zara F, Scheffer IE (2004) Benign familial neonatal-infantile seizures: characterization of a new sodium channelopathy. Annals of neurology 55 (4):550-557. doi:10.1002/ana.20029 7. Liao Y, Deprez L, Maljevic S, Pitsch J, Claes L, Hristova D, Jordanova A, Ala-Mello S, Bellan-Koch A, Blazevic D, Schubert S, Thomas EA, Petrou S, Becker AJ, De Jonghe P, Lerche H (2010) Molecular correlates of age-dependent seizures in an inherited neonatal-infantile epilepsy. Brain : a journal of neurology 133 (Pt 5):1403-1414. doi:10.1093/brain/awq057

8. Scalmani P, Rusconi R, Armatura E, Zara F, Avanzini G, Franceschetti S, Mantegazza M (2006) Effects in neocortical neurons of mutations of the $\mathrm{Na}_{\mathrm{v}} 1.2 \mathrm{Na}^{+}$channel causing benign familial neonatal-infantile seizures. The Journal of Neuroscience 26 (40):10100-10109

9. Ogiwara I, Ito K, Sawaishi Y, Osaka H, Mazaki E, Inoue I, Montal M, Hashikawa T, Shike T, Fujiwara T (2009) De novo mutations of voltage-gated sodium channel $\alpha$ II gene SCN2A in intractable epilepsies. Neurology 73 (13):1046-1053 10. Kobayashi K, Ohzono H, Shinohara M, Saitoh M, Ohmori I, Ohtsuka Y, Mizuguchi M (2012) Acute encephalopathy with a novel point mutation in the SCN2A gene. Epilepsy research 102 (1-2):109-112. doi:10.1016/j.eplepsyres.2012.04.016 
11. Carvill GL, Heavin SB, Yendle SC, McMahon JM, O'Roak BJ, Cook J, Khan A, Dorschner MO, Weaver M, Calvert S (2013) Targeted resequencing in epileptic encephalopathies identifies de novo mutations in CHD2 and SYNGAP1. Nature Genetics 45 (7):825-830

12. Nakamura K, Kato M, Osaka H, Yamashita S, Nakagawa E, Haginoya K, Tohyama J, Okuda M, Wada T, Shimakawa S, Imai K, Takeshita S, Ishiwata H, Lev D, Lerman-Sagie T, Cervantes-Barragan DE, Villarroel CE, Ohfu M, Writzl K, Gnidovec Strazisar B, Hirabayashi S, Chitayat D, Myles Reid D, Nishiyama K, Kodera H, Nakashima M, Tsurusaki Y, Miyake N, Hayasaka K, Matsumoto N, Saitsu H (2013) Clinical spectrum of SCN2A mutations expanding to Ohtahara syndrome. Neurology 81 (11):992-998. doi:10.1212/WNL.0b013e3182a43e57

13. Baasch AL, Hüning I, Gilissen C, Klepper J, Veltman JA, Gillessen-Kaesbach G, Hoischen A, Lohmann K (2014) Exome sequencing identifies a de novo $S C N 2 A$ mutation in a patient with intractable seizures, severe intellectual disability, optic atrophy, muscular hypotonia, and brain abnormalities. Epilepsia 55 (4):e25-e29

14. Matalon D, Goldberg E, Medne L, Marsh ED (2014) Confirming an expanded spectrum of SCN2A mutations: a case series. Epileptic Disorders $16(1): 13-18$

15. Kamiya K, Kaneda M, Sugawara T, Mazaki E, Okamura N, Montal M, Makita N, Tanaka M, Fukushima K, Fujiwara T, Inoue Y, Yamakawa K (2004) A nonsense mutation of the sodium channel gene $S C N 2 A$ in a patient with intractable epilepsy and mental decline. The Journal of neuroscience : the official journal of the Society for Neuroscience 24 (11):2690-2698. doi:10.1523/JNEUROSCI.3089-03.2004

16. Lemke JR, Riesch E, Scheurenbrand T, Schubach M, Wilhelm C, Steiner I, Hansen J, Courage C, Gallati S, Burki S, Strozzi S, Simonetti BG, Grunt S, Steinlin M, Alber M, Wolff M, Klopstock T, Prott EC, Lorenz R, Spaich C, Rona S, Lakshminarasimhan M, Kroll J, Dorn T, Kramer G, Synofzik M, Becker F, Weber YG, Lerche H, Bohm D, Biskup S (2012) Targeted next generation sequencing as a diagnostic tool in epileptic disorders. Epilepsia 53 (8):1387-1398. doi:10.1111/j.1528-1167.2012.03516.x

17. Lauxmann S, Boutry-Kryza N, Rivier C, Mueller S, Hedrich UB, Maljevic S, Szepetowski P, Lerche H, Lesca G (2013) An SCN2A mutation in a family with infantile seizures from Madagascar reveals an increased subthreshold $\mathrm{Na}^{+}$ current. Epilepsia 54 (9):e117-121. doi:10.1111/epi.12241

18. Du W, Bautista JF, Yang H, Diez-Sampedro A, You SA, Wang L, Kotagal P, Luders HO, Shi J, Cui J, Richerson GB, Wang QK (2005) Calcium-sensitive potassium channelopathy in human epilepsy and paroxysmal movement disorder. Nat Genet 37 (7):733-738. doi:10.1038/ng1585 
19. Guerrini R, Sanchez-Carpintero R, Deonna T, Santucci M, Bhatia KP, Moreno T, Parmeggiani L, Bernardina BD (2002) Early-onset absence epilepsy and paroxysmal dyskinesia. Epilepsia 43 (10):1224-1229

20. Marini C, Conti V, Mei D, Battaglia D, Lettori D, Losito E, Bruccini G, Tortorella G, Guerrini R (2012) PRRT2 mutations in familial infantile seizures, paroxysmal dyskinesia, and hemiplegic migraine. Neurology 79 (21):2109-2114 21. Zuberi S, Eunson L, Spauschus A, De Silva R, Tolmie J, Wood N, McWilliam R, Stephenson J, Kullmann D, Hanna M (1999) A novel mutation in the human voltage-gated potassium channel gene (Kv1. 1) associates with episodic ataxia type 1 and sometimes with partial epilepsy. Brain : a journal of neurology 122 (5):817-825

22. Scholl UI, Choi M, Liu T, Ramaekers VT, Häusler MG, Grimmer J, Tobe SW, Farhi A, Nelson-Williams C, Lifton RP (2009) Seizures, sensorineural deafness, ataxia, mental retardation, and electrolyte imbalance (SeSAME syndrome) caused by mutations in KCNJ10. Proceedings of the National Academy of Sciences 106 (14):5842-5847

23. Escayg A, De Waard M, Lee DD, Bichet D, Wolf P, Mayer T, Johnston J, Baloh R, Sander T, Meisler MH (2000) Coding and noncoding variation of the human calcium-channel $\beta$ 4-subunit gene CACNB4 in patients with idiopathic generalized epilepsy and episodic ataxia. The American Journal of Human Genetics 66 (5):1531-1539

24. Specchio N, Vigevano F (2006) The spectrum of benign infantile seizures. Epilepsy research 70:156-167

25. Strupp M, Kalla R, Claassen J, Adrion C, Mansmann U, Klopstock T, Freilinger T, Neugebauer H, Spiegel R, Dichgans M, Lehmann-Horn F, Jurkat-Rott K, Brandt T, Jen JC, Jahn K (2011) A randomized trial of 4-aminopyridine in EA2 and related familial episodic ataxias. Neurology 77 (3):269-275. doi:10.1212/WNL.0b013e318225ab07

26. Strupp M, Kalla R, Dichgans M, Freilinger T, Glasauer S, Brandt T (2004) Treatment of episodic ataxia type 2 with the potassium channel blocker 4-aminopyridine. Neurology 62 (9):1623-1625

27. Dreissen YE, Tijssen MA (2012) The startle syndromes: physiology and treatment. Epilepsia 53 Suppl 7:3-11. doi:10.1111/j.1528-1167.2012.03709.x

28. Jen JC, Graves TD, Hess EJ, Hanna MG, Griggs RC, Baloh RW, investigators C (2007) Primary episodic ataxias: diagnosis, pathogenesis and treatment. Brain : a journal of neurology 130 (Pt 10):2484-2493. doi:10.1093/brain/awm126 29. Tan SV, Wraige E, Lascelles K, Bostock H (2013) Episodic ataxia type 1 without episodic ataxia: the diagnostic utility of nerve excitability studies in individuals with KCNA1 mutations. Developmental medicine and child neurology 55 (10):959-962. doi:10.1111/dmcn.12236

30. Wolff M, Loddenkemper T, Jillella D, Docker M, Wong-Kisiel LC, Møller RS, Weckhuysen S, Ceulemans B, Klepper J, Baumeister FA, Koolen DA, Kluger G ( 2014) SCN2A-related epileptic encephalopathies: extended 
phenotype and response to sodium channel blockers. Paper presented at the 11th European Congress on Epileptology, Stockholm, 02.07.2014

31. Pothmann L, Muller C, Averkin RG, Bellistri E, Miklitz C, Uebachs M, Remy S, Menendez de la Prida L, Beck H (2014) Function of inhibitory micronetworks is spared by $\mathrm{Na}^{+}$channel-acting anticonvulsant drugs. The Journal of neuroscience : the official journal of the Society for Neuroscience 34 (29):9720-9735. doi:10.1523/JNEUROSCI.239513.2014

32. Misra SN, Kahlig KM, George AL, Jr. (2008) Impaired Nav1.2 function and reduced cell surface expression in benign familial neonatal-infantile seizures. Epilepsia 49 (9):1535-1545. doi:10.1111/j.1528-1167.2008.01619.x

33. Schaller KL, Caldwell JH (2003) Expression and distribution of voltage-gated sodium channels in the cerebellum. Cerebellum 2 (1):2-9. doi:10.1080/14734220309424

34. Touma M, Joshi M, Connolly MC, Ellen Grant P, Hansen AR, Khwaja O, Berry GT, Kinney HC, Poduri A, Agrawal PB (2013) Whole genome sequencing identifies $S C N 2 A$ mutation in monozygotic twins with Ohtahara syndrome and unique neuropathologic findings. Epilepsia 54 (5):e81-e85 
Tables

Table 1 Main phenotypic characteristics of all four patients

\begin{tabular}{|c|c|c|c|c|}
\hline & Patient \#1 (*2004) & Patient \#2 (*2006) & Patient \#3 (*2011) & Patient \#4 (*1999) \\
\hline Mutation & c. $5644 \mathrm{C}>\mathrm{G} / \mathrm{p} . \mathrm{R} 1882 \mathrm{G}$ & $\begin{array}{l}\text { c. } 4565 \mathrm{G}>\mathrm{C} / \mathrm{p} \cdot \mathrm{G} 1522 \mathrm{~A} \\
\text { c. } 5644 \mathrm{C}>\mathrm{G} / \mathrm{p} \cdot \mathrm{R} 1882 \mathrm{G}\end{array}$ & c. $788 \mathrm{C}>\mathrm{T} / \mathrm{p} . \mathrm{A} 263 \mathrm{~V}$ & c. $788 \mathrm{C}>$ T/p.A263V \\
\hline Gender & male & female & male & male \\
\hline Exam at birth & $\begin{array}{l}\text { EEG at } 42 \text { con- } \\
\text { ceptional weeks } \\
\text { slightly abnormal (see } \\
\text { text) }\end{array}$ & $\begin{array}{l}\text { suspected amniotic } \\
\text { infection syndrome }\end{array}$ & $\begin{array}{l}\text { muscular hypotonia } \\
\text { and sleepiness }\end{array}$ & $\begin{array}{l}\text { hypomotor activity } \\
\text { followed by TCS on } \\
\text { alternating sides with } \\
\text { contralateral ictal EEG } \\
\text { discharges }\end{array}$ \\
\hline $\begin{array}{l}\text { Age at seizure } \\
\text { onset }\end{array}$ & $2 \mathrm{~d}$ & $24 \mathrm{~d}$ & $7 \mathrm{~d}$ & $1 \mathrm{~d}$ \\
\hline $\begin{array}{l}\text { Seizure type at } \\
\text { onset }\end{array}$ & $\begin{array}{l}\text { bilateral TCS with } \\
\text { reduced oxygen } \\
\text { saturation and } \\
\text { unresponsiveness }\end{array}$ & $\begin{array}{l}\text { multifocal CS and } \\
\text { TCS lasting } 10 \mathrm{~s} \text { to } \\
2 \mathrm{~min} .\end{array}$ & bilateral TS & $\begin{array}{l}\text { TCS on alternating } \\
\text { sides }\end{array}$ \\
\hline $\begin{array}{l}\text { Other seizure } \\
\text { types }\end{array}$ & $\begin{array}{l}\text { TCS, tendency to } \\
\text { clustering }\end{array}$ & $\begin{array}{l}\text { GTCS during febrile } \\
\text { infection }\end{array}$ & $\begin{array}{l}\text { TS evolving into } \\
\text { secondary GTCS }\end{array}$ & GTCS \\
\hline $\begin{array}{l}\text { Treatment } \\
\text { (duration) }\end{array}$ & $\begin{array}{l}\text { PB ( } 7 \text { mo }) ; \\
\text { Acetazolamide } \\
(4 \mathrm{mo}) ; \\
\text { VPA }(10 \mathrm{y})\end{array}$ & $\begin{array}{l}\text { PB ( } 5 \text { mo }) ; \text { CLZ+PHT } \\
\text { ( } 2 \text { weeks); } \\
\text { VPA }\left(6 \frac{1}{2} \mathrm{y}\right)\end{array}$ & $\begin{array}{l}\text { Vit B6 (brief); PB } \\
\text { (brief); TPM (brief); } \\
\text { LEV (14 mo); OXC } \\
\text { (3 y); LTG (5 mo); }\end{array}$ & $\begin{array}{l}\text { After Liao et al, } \\
\text { 2010[3]: 4-AP (12 d); } \\
\text { Propranolol ( } 7 \mathrm{mo}) ; \\
\text { TPM (10 mo); } \\
\text { LTG (7 mo) }\end{array}$ \\
\hline $\begin{array}{l}\text { Seizure outcome } \\
\text { (age) }\end{array}$ & $\begin{array}{l}\text { seizure-free } \\
\text { (since age } 5 \mathrm{mo} \text { ) }\end{array}$ & $\begin{array}{l}\text { seizure-free } \\
\text { (since age } 5 \mathrm{mo} \text { ) }\end{array}$ & $\begin{array}{l}\text { seizure-free } \\
\text { (since age } 7 \mathrm{mo} \text { ) }\end{array}$ & $\begin{array}{l}\text { seizure-free (since age } \\
13 \mathrm{mo}) \text {, isolated sei- } \\
\text { zures }(3.5,6.5,14.5 \mathrm{y})\end{array}$ \\
\hline $\begin{array}{l}\text { Symptoms during } \\
\text { childhood-onset } \\
\text { episodic attacks }\end{array}$ & $\begin{array}{l}\text { paroxysmal dizziness } \\
\text { and poor balance, } \\
\text { slurred speech, ataxia, } \\
\text { nausea, headache } \\
\text { without vomiting }\end{array}$ & $\begin{array}{l}\text { slurred speech, } \\
\text { impaired balance, } \\
\text { ataxic gait, headache, } \\
\text { rarely vomiting }\end{array}$ & $\begin{array}{l}\text { dizziness, unsteady } \\
\text { gait, inability to walk, } \\
\text { possibly rare painful } \\
\text { episodes }\end{array}$ & $\begin{array}{l}\text { poor balance, ataxia, } \\
\text { slurred speech, inter- } \\
\text { mittent myoclonic } \\
\text { jerks, severe distress } \\
\text { with headache, back } \\
\text { pain, hypermotor acti- } \\
\text { vity, hyperventilation, } \\
\text { retching or vomiting }\end{array}$ \\
\hline $\begin{array}{l}\text { Age at onset, freq. } \\
\text { and duration of } \\
\text { episodes }\end{array}$ & $\begin{array}{l}3.7 \mathrm{y} ; 1-2 / \mathrm{mo} ; \text { a few } \\
\text { min to several h }\end{array}$ & $\begin{array}{l}20 \mathrm{mo} ; 1-10 / \mathrm{w} ; 1-5 \\
\min (\text { rarely repeating } \\
\text { over } 2 \mathrm{~h})\end{array}$ & $15 \mathrm{mo} ; 2-3 / \mathrm{mo} ; 1 \mathrm{~d}$ & $\begin{array}{l}1.5 \mathrm{y} ; 1-3 / \mathrm{mo} \\
\text { several h }\end{array}$ \\
\hline
\end{tabular}


*: year of birth; 4-AP: 4-aminopyridine; CLZ: clonazepam; d: day(s); CS: clonic seizure; GTCS: generalized tonicclonic seizure; h: hour(s); LTG: Lamotrigine; LEV: levetiracetam; min: minute(s); mo: month(s); OXC: oxcarbazepine; PB: phenobarbitone; PHT: Phenytoin; s: second(s); TS: tonic seizure; TCS: tonic clonic seizure; TPM: topiramate; VPA: valproate; w: week(s), y: year(s)

Table 2 Current density and gating parameters for $\mathrm{Na}_{\mathrm{v}} 1.2 \mathrm{WT}$ and the mutations

\begin{tabular}{|c|c|c|c|c|c|c|c|c|}
\hline & \multirow[b]{2}{*}{$\mathrm{CD}[\mathrm{pA} / \mathrm{pF}]$} & \multicolumn{2}{|c|}{ Steady-state activation } & \multicolumn{3}{|c|}{ Steady-state inactivation } & \multicolumn{2}{|l|}{$\mathbf{T}_{\text {rec }}[\mathrm{ms}]$} \\
\hline & & $\mathrm{V}_{1 / 2}[\mathrm{mV}]$ & $\mathbf{k}$ & $\mathrm{V}_{1 / 2}[\mathrm{mV}]$ & $\mathbf{k}$ & $\mathbf{N}$ & at $-100 \mathrm{mV}$ & $\mathbf{N}$ \\
\hline$S C N 2 A-\mathrm{WT}$ & $-450.9 \pm 54.8$ & $-28.2 \pm 1.0$ & $-5.7 \pm 0.2$ & $-69.4 \pm 0.7$ & $5.2 \pm 0.1$ & 16 & $5.2 \pm 0.4$ & 10 \\
\hline R1882G & $-356.7 \pm 57.2$ & $-31.8 \pm 1.0^{\$}$ & $-5.8 \pm 0.3$ & $-67.8 \pm 0.8$ & $5.7 \pm 0.3$ & 12 & $5.8 \pm 0.6$ & 12 \\
\hline G1522A & $-448.0 \pm 78.1$ & $-29.0 \pm 1.3$ & $-5.3 \pm 0.3$ & $-68.5 \pm 0.8$ & $5.1 \pm 0.2$ & 12 & $5.0 \pm 0.5$ & 12 \\
\hline $\begin{array}{l}\text { G1522A/ } \\
\text { R1882G }\end{array}$ & $-757.4 \pm 136.3^{\#}$ & $-28.8 \pm 1.2$ & $-4.8 \pm 0.3 *$ & $-64.3 \pm 0.9^{\&}$ & $5.2 \pm 0.1$ & 11 & $4.0 \pm 0.4$ & 11 \\
\hline
\end{tabular}

Data are presented as means \pm s.e.m. k: slope factor.

$\$$ the R1882G mutant is significantly different from the WT ( $<<0.05$, t-test).

\#the G1522A/R1882G double mutant is significantly different from the three other clones $(p<0.05$, one way ANOVA with Bonferroni posthoc test).

*the G1522A/R1882G double mutant is significantly different from the R1882G mutant ( $\mathrm{p}<0.05$, one way ANOVA with Bonferroni posthoc test).

\&the G1522A/R1882G double mutant is significantly different from WT ( $<0.001)$, from G1522A ( $<0.01)$ and R1882G ( $<<0.05$, one way ANOVA with Bonferroni posthoc test) 


\section{Figure legends}

Fig.1 Pedigrees and $S C N 2 A$ mutations in three additional cases with neonatal epilepsy and late-onset episodic ataxia. (ac) Pedigrees of patients \#1 (a), \#2 (b) and \#3 (c). The index patients are indicated by arrows. "+" denotes a wild type allele. A grandmother with reported Menière's disease (a) and an aunt with reported neonatal-onset seizures (c) are marked in gray. Patients \#1 and \#3 carry one de novo SCN2A mutation each (a, c), whereas patient \#2 carries both an inherited variant and a de novo SCN2A mutation on the same allele (b). (d) Sequence chromatograms of patient \#2 and the unaffected parents showing a previously described, heterozygous c. $4565 \mathrm{G}>\mathrm{C}$ variant in the father and the patient, and an additional c.5644C $>\mathrm{G}$ mutation only in the patient. (e) Structure of the human $\mathrm{Na}_{\mathrm{v}} 1.2 \mathrm{Na}^{+}$channel $\alpha$ subunit showing the locations of all three mutations (A263V: orange circle, G1552A: green circle, R1882G: blue circle). (f) A263V, G1522 and R1882 (red boxed) and the surrounding amino acids show high evolutionary conservation

Fig.2 Functional studies reveal a gain-of-function for the R1882G mutation. (a-b) Families of whole-cell $\mathrm{Na}^{+}$currents recorded from tsA-201 cells transfected with either SCN2A-WT (a) or R1882G (b) mutant channels. Sodium currents were elicited by $24 \mathrm{~ms}$ long step depolarizations ranging from -105 to $+97.5 \mathrm{mV}$ from a holding potential of $-140 \mathrm{mV}$. (c) The current density revealed no significant change in mean whole-cell peak current for R1882G mutant channels. (d) Voltage-dependence of steady-state $\mathrm{Na}^{+}$channel activation and inactivation revealing a significant hyperpolarizing shift in the activation curve for R1882G mutant channels compared with the WT (*p<0.05, t-test). Lines represent fits of Boltzman functions. (e) The time course of recovery from fast inactivation determined at -100 $\mathrm{mV}$ showed no significant changes between WT and mutant channels. Lines represent fits of exponential functions yielding the time constant $\mathrm{T}_{\text {rec. }}$. All values of electrophysiological results, numbers and p-values are listed in Table 2 and are shown as mean \pm SEM

Fig.3 Functional studies reveal a different gain-of-function mechanism when both mutations G1522A/R1882G are combined. (a-c) Families of whole-cell $\mathrm{Na}^{+}$currents recorded from tsA-201 cells transfected with either SCN2A-WT (a), G1522A mutant channels (b) or G1522A/R1882G mutant channels (c). Sodium currents were elicited as in Fig. 2. (d) The current density was significantly (1.7-fold) increased for G1522A/R1882G mutant channels $(* \mathrm{p}<0.05$, one way ANOVA with Bonferroni posthoc test, Table 2). (e) Voltage-dependence of steady-state $\mathrm{Na}^{+}$channel activation and inactivation revealing a significant depolarizing shift of the inactivation curve for G1522A/R1882G mutant channels (from WT $* * * \mathrm{p}<0.001$, from G1522A **p $<0.01$, one way ANOVA with Bonferroni posthoc test, Table 2). Lines represent fits of Boltzman functions. (f) Time course of recovery from fast inactivation at $-100 \mathrm{mV}$, as described in Fig. 2, did not reveal significant changes between WT and mutant channels. All values of electrophysiological results, numbers and $\mathrm{p}$-values are listed in Table 2 and are shown as mean \pm SEM 
Fig.4 Western Blot Analysis shows a significant increase in expression level only for the G1522A/R1882G mutation. (a) Representative experiment illustrating total $\mathrm{Na}_{\mathrm{v}} 1.2$ protein expression of tsA201 cells transfected with: only transfection reagent as Mock control, WT-Nav1.2, only G1522A, only R1882G or both G1522A/R1882G and detected with anti- pan sodium channel antibody. The immunoreactive bands of Mock-control, Nav1.2-WT or mutant proteins were normalized to the amount of the endogenous membrane-cytoskeletal protein Vinculin. (b) Quantification of six independent experiments by normalizing the signals of Nav1.2 protein bands to the corresponding Vinculin signals in total lysates demonstrated that each mutation exposed a higher level of $\mathrm{Na}^{+}$channel expression, but only G1522A/R1882G presented a significant increase of the expression level compared to the WT $(* * \mathrm{p}<0.01 ; \mathrm{N}=6$, one way ANOVA with Bonferroni posthoc test). All values are shown as mean \pm SEM 

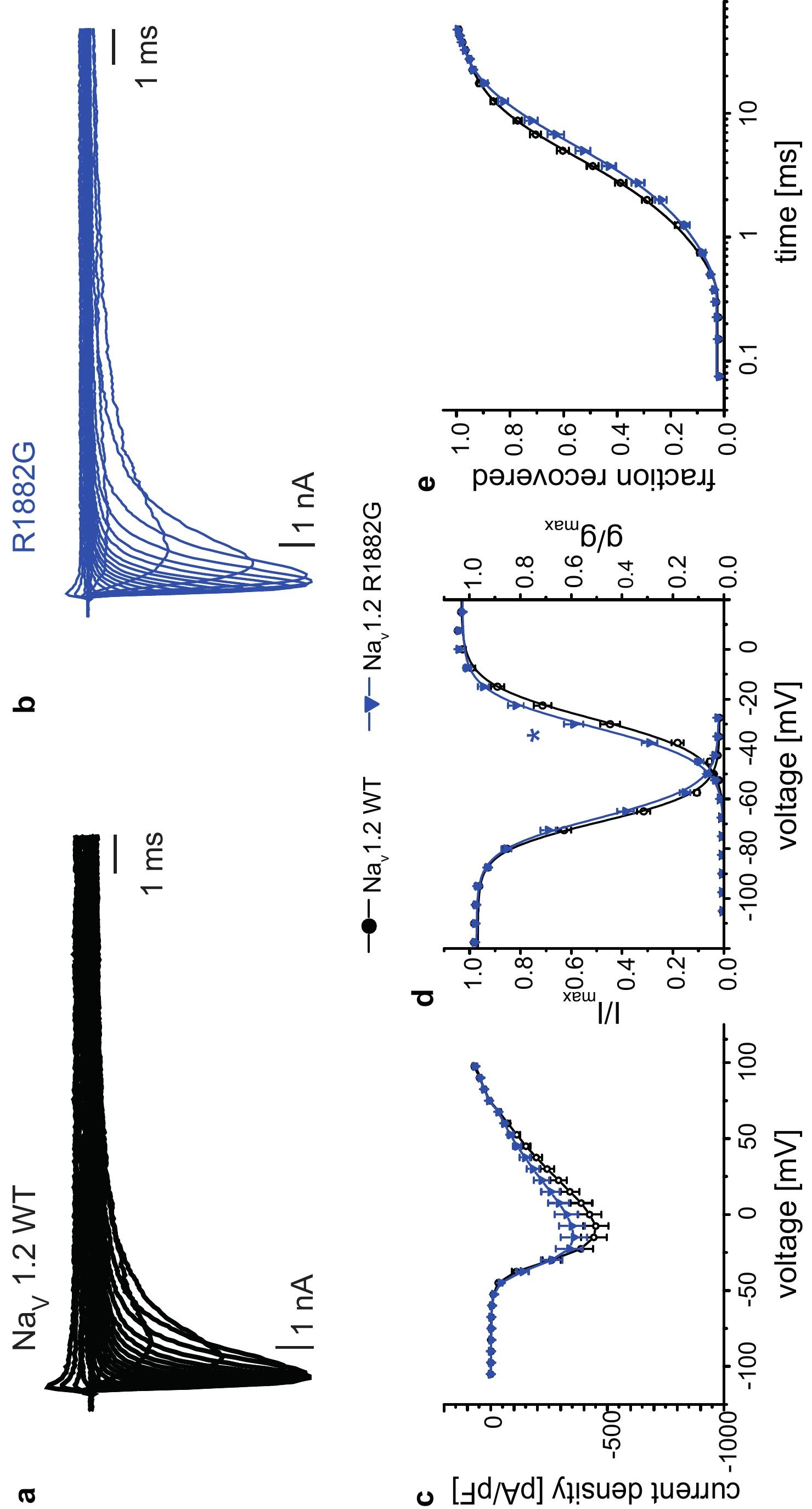


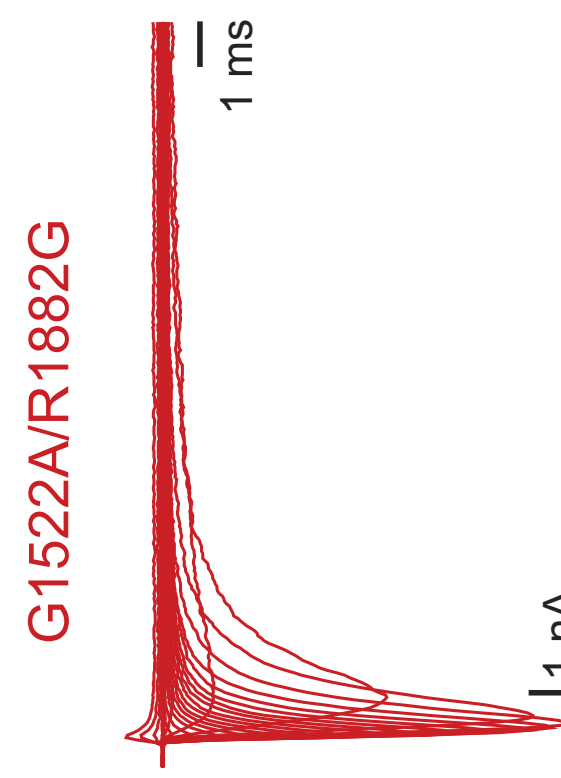

0
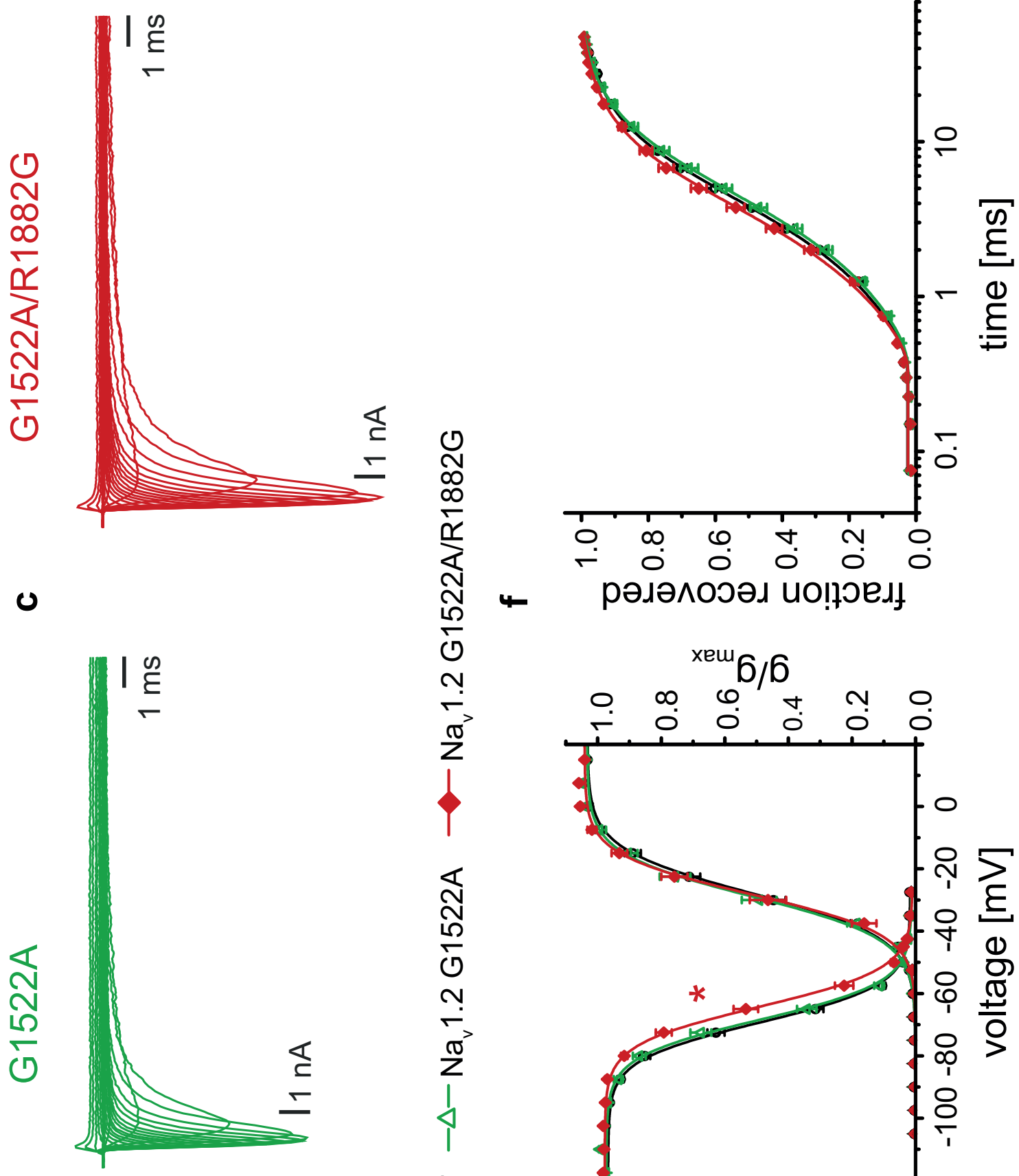

으
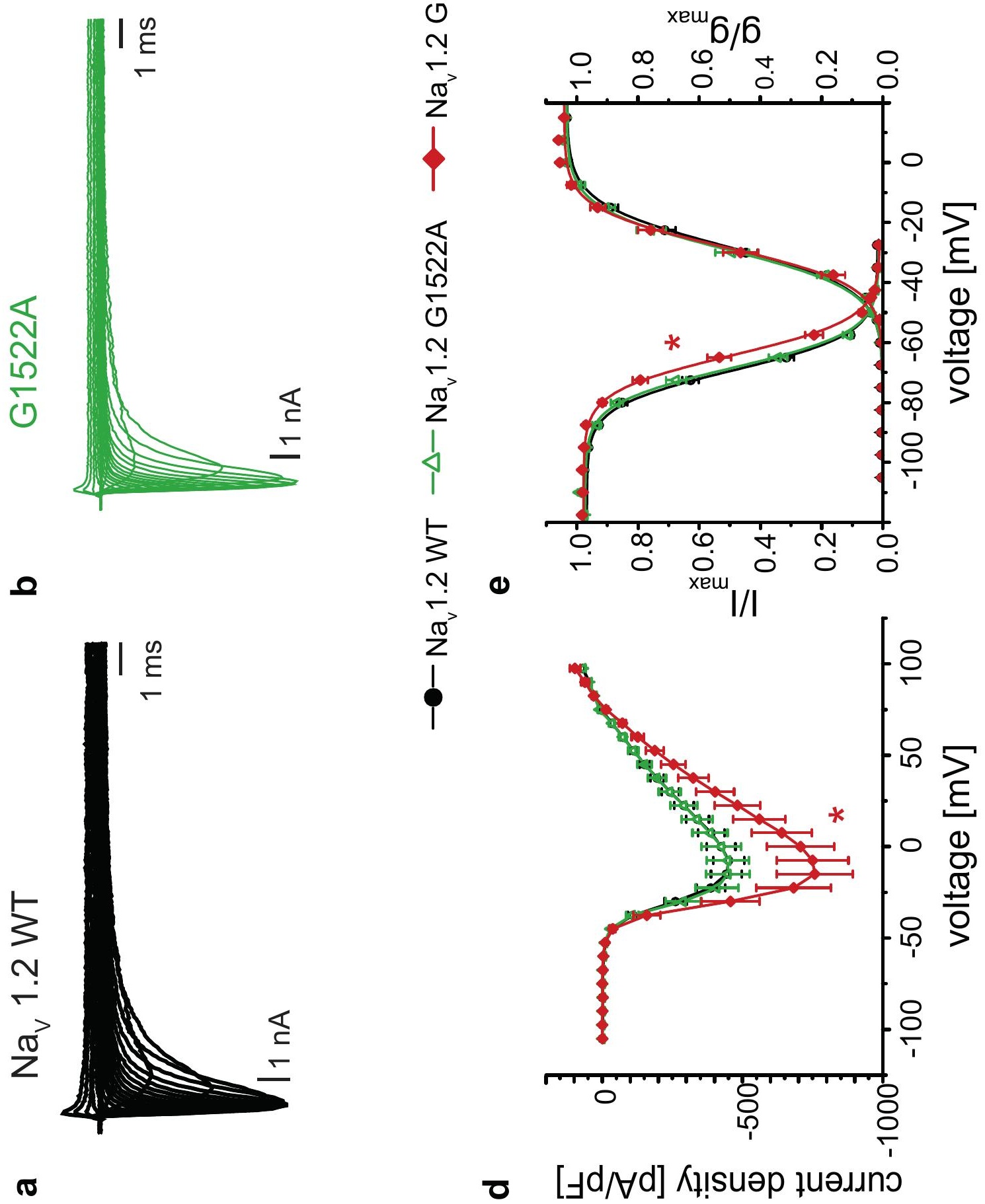

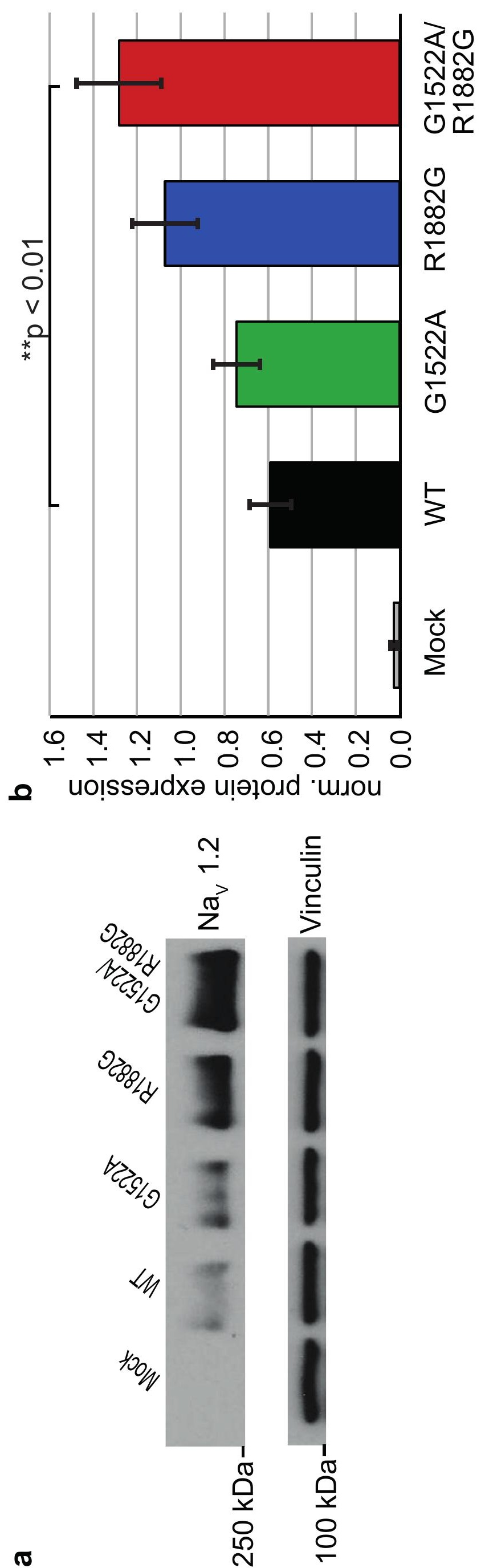
Click here to access/download Supplementary Material ESM_1_Resubmission.docx 